\title{
Correction to: Modeling the spatio-temporal dynamics of air pollution index based on spatial Markov chain model
}

\author{
Yousif Alyousifi - Kamarulzaman Ibrahim • \\ Wei Kang • Wan Zawiah Wan Zin
}

Published online: 8 November 2020

(C) Springer Nature Switzerland AG 2020

\section{Correction to: Environ Monit Assess (2020) 192:719 \\ https://doi.org/10.1007/s10661-020-08666-8}

The original version of this article unfortunately contained an error in the affiliation section and in the main body text.

In the affiliation section, affiliations 1 and 2 should be merged as the authors have the same affiliation. The corrected affiliation section is shown below.

The sentence under Results and discussion and Air pollution evaluation analysis sections under paragraph 2 contained an error. The month "May" should be corrected as "June". The corrected sentence is shown below.
It could be seen that most stations have experienced the highest API level in the month of June 2013.

In Table 4, the value " 0.2828579 (5)" should be corrected as 0.22729 (5).

The original article has been corrected.

Publisher's note Springer Nature remains neutral with regard to jurisdictional claims in published maps and institutional affiliations.

The online version of the original article can be found at https://doi.org/10.1007/s10661-020-08666-8

Y. Alyousifi $(\bowtie) \cdot K$. Ibrahim • W. Z. W. Zin

Department of Mathematical Sciences, Faculty of Science and Technology, Universiti Kebangsaan Malaysia, 43600 Bangi,

Selangor, Malaysia

e-mail: p90499@siswa.ukm.edu.my

W. Kang

Center for Geospatial Sciences, University of California,

Riverside, CA, USA 